\title{
Studies on Ali-esterases
}

\section{SUBSTRATE SPECIFICITY OF THE ESTERASES OF SOME SAPROPHYTIC MYCOBACTERIA*}

\author{
By D. K. MYERS, $\uparrow$ JUSTINA W. TOL ANd MARIA H. T. DE JONGE \\ Pharmaco-therapeutic Laboratory, University of Amsterdam, Amsterdam, Holland
}

(Received 26 June 1956)

Recent investigations by Mendel, Myers, Uyldert, Ruys \& de Bruyn (1953) and by Ruys (1954) have shown that the growth of Mycobacterium tuberculosis can be inhibited by relatively small amounts of various organophosphorus compounds under specified conditions. A similar finding had been briefly reported for Lactobacillus arabinosus (C. Haber, quoted by Brooks, Ransmeier \& Gerard, 1949). However, Mendel et al. (1953) further pointed out that the concentrations of the organophosphorus compounds required to inhibit the growth of the mycobacteria corresponded closely with the concentrations which inhibit the ali-esterases of these bacilli.

Further investigations showed that the growth of certain strains of saprophytic mycobacteria was also very sensitive to inhibition by the organophosphorus compounds (Ruys, unpublished results), whereas the growth of other strains was scarcely affected. This observation offered an opportunity to investigate the suggested correlation between the effects of these inhibitors on the growth and on the ali-esterases of the mycobacteria. In the course of these investigations, it became apparent that some of the mycobacteria must contain more than one ali-esterase. The substrate specificities and other characteristics of these enzymes were therefore studied with the aid of selective inhibitors as described in previous investigations (cf. Myers, 1956).

\section{EXPERIMENTAL}

Substrates and inhibitors. The substrates included the esters used in previous investigations (Myers, Schotte, Boer \& Borsje-Bakker, 1955; Myers, 1956) together with ethyl phenylacetate (Wislicenus, 1897), acetanilide and butyranilide (Gerhardt, 1853).

The inhibitors used were diethyl $p$-nitrophenyl phosphate (E600, paraoxon), diisopropyl $p$-nitrophenyl phosphate (DINP), and phenyl $N$-n-propylcarbamate. E600 and DINP were obtained through the courtesy of Albright and Wilson Ltd., London. Phenyl $N$ - $n$-propylcarbamate (m.p. 53-54 ${ }^{\circ}$ after recrystallization from $n$-hexane) was synthesized from phenol and $n$-propyl isocyanate by the

* Part 4: Myers (1956).

$\dagger$ Present address: Suffield Experimental Station, Ralston, Alberta, Canada. general method of Kobezen, Metcalf \& Fuhuto (1954); the isocyanate derivative was prepared by the procedure described by Schroeter (1909).

Determination of esterase activity. Esterase activity was measured by a manometric method in the Warburg apparatus at $37.5^{\circ}$ and $\mathrm{pH} 7.4$ in a medium containing $0 \cdot 025 \mathrm{M}-\mathrm{NaHCO}_{3}$ and saturated with $\mathrm{CO}_{2}+\mathrm{N}_{2}(5: 95, \mathrm{v} / \mathrm{v})$. Preliminary experiments at $25^{\circ}$ and $37.5^{\circ}$ indicated that the latter temperature was suitable for measuring the esterase activities of the saprophytic mycobacteria as well as those of mammalian tissues. The amount of enzyme preparation was usually adjusted so that the activity was in the range of 2-8 $\mu$ l. of $\mathrm{CO}_{2} / \mathrm{min}$. in each experiment. The reaction mixture was incubated for $30 \mathrm{~min}$. at $37 \cdot 5^{\circ}$ with or without inhibitor before adding a small volume of substrate, in order to determine the residual esterase activity. All esters were prepared in the form of an aqueous emulsion, suspension or solution containing $5 \%(\mathrm{w} / \mathrm{v})$ of gum acacia; the final concentrations of ester and gum acacia in the reaction mixture were 0.2 and $0.1 \%(w / v)$ respectively. The esterase activity was calculated from the initial constant rate of hydrolysis of the substrate after the appropriate corrections had been made for slow spontaneous hydrolysis.

The rate of hydrolysis of butyranilide and acetanilide was also measured by the manometric technique described above (cf. Michel, Bernheim \& Bernheim, 1937); in this case, the concentration of substrate was increased to $1 \%(w / v)$. Although the activities were measurable, the data obtained with these substrates are complicated by the relative insolubility of the anilides in water. Butyranilide appeared to be less soluble than acetanilide; this is probably responsible for the fact that butyranilide appeared to be less rapidly hydrolysed than acetanilide by some of the enzymes investigated.

Enzyme preparations. Aqueous homogenates of rat brain and liver were prepared with a glass Potter-Elvehjem homogenizer. As noted previously, the brain suspensions contain several esterases; all of the experiments described here are concerned only with the 'DINP-sensitive' esterase, which is responsible for about $70 \%$ of the total activity towards tributyrin and for all of the activity towards ethyl butyrate (Myers, 1956). The liver also contains several enzymes with the characteristics of ali-esterases (Falconer \& Taylor, 1946; Fodor, 1946; Myers \& Mendel, 1953; Myers, Kemp, Tol \& de Jonge, unpublished results); the enzyme studied in the present investigation is responsible for more than $90 \%$ of the total activity towards tributyrin and for $99 \%$ of the total activity towards ethyl butyrate and phenyl butyrate (cf. Aldridge, 1954). This esterase would seem to be analogous to the ali-esterase from horse liver which was used by Schwert \& Glaid (1952). 
The mycobacteria were supplied by Professor A. Charlotte Ruys, Laboratory of Hygiene, University of Amsterdam. The results obtained in growth experiments with Mycobacterium phlei and a similar strain of saprophytic mycobacteria designated as $\mathrm{S} 3048$ have been described previously (Ruys, 1954). Five other strains of saprophytic mycobacteria isolated from human-stomach washings were also selected for study; these strains have been designated as Myco. A, B, C, D and $\mathrm{E}$ in the present paper. (These strains are numbered as VII, XIV, IX, XII and XV respectively in the collection at the Laboratory of Hygiene.) The hitherto unpublished results obtained by Ruys in preliminary growth experiments with these strains are indicated in Table 1; it is hoped that more extensive results will be published elsewhere.

The ali-esterase content of the saprophytic mycobacteria seemed to be independent of the medium on which they were grown. Almost identical results were obtained with samples of the same strain grown in bouillon, the Dubos medium (cf. Dubos \& Davis, 1946; Dubos \& Middlebrook, 1947), the medium of Proskauer \& Beck (1894; cf. Youmans \& Karlson, 1947), or on the medium of Löwenstein (1930). The activities of the various strains towards tributyrin varied from 50 to $250 \mu \mathrm{l}$. of $\mathrm{CO}_{2} / \mathrm{mg}$. dry wt. of bacteria/hr., but the values obtained were found to be characteristic of the strain in question rather than of the culture medium. The sensitivity of the ali-esterases to inhibition by $\mathrm{E} 600$ under the experimental conditions was also independent of the medium on which the bacteria had been grown.

The synthetic medium of Proskauer \& Beck (1894) appeared to be the most convenient for culturing large amounts of mycobacteria; most of the experiments on the ali-esterases were carried out with mycobacteria which had been grown on this medium. The mycobacteria were harvested after they had been grown for 4 weeks at $37^{\circ}$; they were centrifuged down from the culture medium at $3000 \mathrm{rev} . / \mathrm{min}$. in a clinical centrifuge, washed with boiled water to remove the last traces of the culture medium together with any extracellular proteins, and resuspended in water with the aid of a Potter-Elvehjem homogenizer. The bacterial suspensions were stored at $0^{\circ}$ until used. All experiments reported in this paper were carried out within
4 days after preparation of the bacterial suspension; however, the activity of the ali-esterases did not deteriorate appreciably within 2 weeks under these conditions.

\section{RESULTS}

The initial experiments on the inhibition of bacterial growth by organophosphorus compounds were carried out with Mycobacterium tuberculosis typus humanus H $37 \mathrm{Rv}$; the growth in the Dubos medium at $37^{\circ}$ was delayed for several days in the presence of $10^{-5} \mathrm{M}$ E 600 (Mendel et al. 1953; Ruys, 1954). DINP, the isopropyl analogue of $\mathrm{E} 600$, is considerably more active than $\mathrm{E} 600$ in preventing the growth of the tubercle bacilli (Ruys, unpublished results; see Table 1); this is presumably due to the greater stability of DINP in the Dubos medium. $\mathrm{E} 600$, in contrast to DINP, is slowly broken down by the A-esterase present in the human-serum albumin which is a component of the Dubos medium (Ruys, 1954; cf. Aldridge, 1953).

Mendel et al. (1953) showed that the ali-esterase of the tubercle bacilli is strongly inhibited by $\mathbf{E} 600$; however, accurate measurements of the esterase activity with the Warburg apparatus were not carried out owing to the high pathogenicity of these bacilli. Two strains of non-pathogenic mycobacteria, Myco. phlei and S 3048, were therefore investigated by Ruys (1954; unpublished results). Although the ali-esterases of both of these strains were almost completely inhibited by $10^{-5} \mathrm{M} \mathrm{E} 600$ within $30 \mathrm{~min}$. at $37^{\circ}$ in the Warburg apparatus, the rate of growth in the Dubos medium at $37^{\circ}$ was not significantly affected by the same concentration of E600. It seemed possible that this finding might be explained by the rapid growth of these bacilli at $37^{\circ}$, since other data indicated that the concentration of E600 required to prevent the growth increases in

\section{Table 1. Effect of E600 and DINP on the growth of several strains of mycobacteria}

Mycobacteria were grown in the Dubos medium at $37^{\circ}$ by the methods described by Mendel et al. (1953) and Ruys (1954). The relative rate of growth was estimated from the time taken to reach a visible turbidity due to the multiplication of the mycobacteria in the medium. This time does not provide an accurate criterion for comparing the rate of growth of different strains of mycobacteria, but does clearly demonstrate the effects of E600 and DINP when the rate of growth is compared with the control experiments which were carried out simultaneously with the same inoculum of a given strain of mycobacteria. The preliminary results given in this table are taken from unpublished studies of Ruys.

\begin{tabular}{|c|c|c|c|}
\hline \multirow[b]{2}{*}{$\begin{array}{c}\text { Strain of } \\
\text { mycobacteria }\end{array}$} & \multicolumn{3}{|c|}{$\begin{array}{l}\text { Relative rate of growth (days to reach a } \\
\text { visible turbidity in the Dubos medium) }\end{array}$} \\
\hline & Control & $\begin{array}{l}\text { In the presence } \\
\text { of } 10^{-5} \mathrm{M} \mathrm{E} 600\end{array}$ & $\begin{array}{c}\text { In the presence } \\
\text { of } 3 \times 10^{-6} \mathrm{M} \\
\text { DINP }\end{array}$ \\
\hline $\begin{array}{l}\text { Myco. tuberculosis } \mathrm{H} 37 \mathrm{Rv} \\
\text { Myco. D } \\
\text { Myco. E } \\
\text { Myco. C } \\
\text { Myco. phlei } \\
\text { Myco. A } \\
\text { Myco. B }\end{array}$ & $\begin{array}{l}3 \\
2 \frac{1}{2} \\
3 \\
4 \\
1 \\
3 \\
2\end{array}$ & $\begin{array}{c}16 \\
(>40) \\
(>85) \\
(>50) \\
1 \\
4 \\
3\end{array}$ & $\begin{array}{c}(>85) \\
(>85) \\
(>85) \\
(>50) \\
- \\
3 \\
2\end{array}$ \\
\hline
\end{tabular}


proportion to the rate of growth (Mendel et al. 1953; Ruys, 1954). To test this possibility, five other strains of saprophytic mycobacteria were studied by Ruys (unpublished results). Her results showed that the growth of three of the five strains was strongly inhibited at $37^{\circ}$ in the Dubos medium by $10^{-5} \mathrm{M}$ E600 or $3 \times 10^{-6} \mathrm{M}$ DINP; however, the growth of the other two strains was not affected by DINP and only slightly affected by E600 (see Table 1). It seemed unlikely that these differences could be explained by the differences in the rate of growth. The ali-esterases of these saprophytic mycobacteria were therefore studied in detail to see if there was any correlation between the effect of the organophosphorus compounds on the growth and on the esterases of the mycobacteria.

\section{Differentiation of the ali-esterases}

In the course of the investigations on the inhibition of the esterases by various compounds, it became apparent that some of the mycobacteria must contain more than one ali-esterase with a measurable activity. The evidence for this conclusion in Myco. phlei and Myco. B is shown in Table 2; the results obtained with the strain designated as $M y c o$. $\mathbf{E}$ are also included in this table for purposes of comparison.

With Myco. E the degree of inhibition of the aliesterase activity increases progressively as the concentration of inhibitor is increased until the esterase activity appears to be completely inhibited (Table 2). These results fail to give any indication for the presence of more than one esterase in $M y c o . \mathrm{E}$ which is capable of hydrolysing ethyl butyrate at a measurable rate. The same type of result was obtained with Myco. C and Myco. D.

With Myco. phlei, on the other hand, the inhibition of the esterase activity towards ethyl butyrate reaches a plateau when the concentration of DINP reaches $10^{-6} \mathrm{M}$; a further increase in the concentration up to $10^{-5} \mathrm{M}$ DINP has little effect on the residual esterase activity (Table 2 and Fig. 1). The existence of this plateau value strongly suggests that Myco. phlei must contain at least two aliesterases capable of hydrolysing ethyl butyrate, one of which is almost completely inhibited by $10^{-6} \mathrm{M}$ DINP, whereas the other is not significantly inhibited before the concentration of DINP is increased above $10^{-5} \mathrm{M}$. A similar plateau value does not appear clearly when phenyl $N$-n-propylcarbamate is used as inhibitor, although the curve relating the esterase activity to the inhibitor concentration is somewhat flattened in the region of $10^{-6} \mathrm{M}$ inhibitor (Fig. 1). However, a marked difference in the sensitivity to this carbamate does become evident when the DINP-resistant esterase activity is measured separately, in the presence of $10^{-5} \mathrm{M}$ DINP to eliminate the activity of the DINP. sensitive esterase. The DINP-resistant activity is almost completely inhibited by $10^{-6} \mathrm{M}$ phenyl $N-n$ propylcarbamate, although the total activity in the absence of DINP is only slightly affected by the same concentration of this compound (Table 2 and Fig. 1). It is probable, therefore, that the DINPresistant activity is due to an esterase which is relatively sensitive to inhibition by the carbamate derivative, whereas the DINP-sensitive activity is due to a second esterase which is less sensitive to the carbamate inhibitor. The DINP-sensitive enzyme, it might be noted, appears to be responsible for the major portion of the total esterase activity towards ethyl butyrate.

Myco. phlei also exhibits a low but measurable activity towards ethyl leucine and butyranilide (Table 3). The results obtained with these substrates confirm the above conclusions. Almost all of the activity of Myco. phlei towards ethylleucine is resistant to inhibition by $10^{-6} \mathrm{M}$ phenyl $N$ - $n$-propylcarbamate and sensitive to inhibition by $10^{-5} \mathrm{M}$ DINP, whereas the activity towards butyranilide shows the reverse pattern, i.e. resistance to inhibition by $10^{-5} \mathrm{M}$ DINP and sensitivity to $10^{-6} \mathrm{M}$ carbamate (Table 3). The relationship between these results and those obtained with ethyl butyrate can be seen most clearly when the inhibition of the esterase activity is plotted against the inhibitor concentration, as in Fig. 1. The characteristics of the two esterases in $M y c o$. phlei are readily apparent from this figure. Most of the activity towards ethylleucine is due to the DINP-sensitive esterase, whereas most of the activity towards butyranilide is due to the DINP-resistant esterase.

The results obtained with $M y c o$. B can be analysed in the same way as described above for the esterases of $M y c o$. phlei. The evidence again points to the presence of two esterases, but in this case the plateau value representing the borderline between the activities of the two esterases is observed with the inhibitor phenyl $N$-n-propylcarbamate and is not distinct with DINP (Table 2). When the activity towards ethyl butyrate is measured in the presence of $10^{-6} \mathrm{M}$ phenyl $N$-n-propylcarbamate to eliminate the activity of the carbamate-sensitive esterase, it becomes apparent that the residual carbamateresistant activity is relatively resistant to inhibition by DINP (Table 2). These results present a contrast to those obtained with Myco. phlei; the carbamate-resistant esterase activity of Myco. phlei is readily inhibited by DINP.

As with Myco. phlei, it is again found that the activities of Myco. B towards ethylleucine and butyranilide are, for the greater portion, due to separate enzymes. Almost all of the activity towards ethylleucine is resistant to inhibition by phenyl $N$-n-propylcarbamate in concentrations up to $10^{-4} \mathrm{M}$, whereas almost all of the activity towards 
Table 2. Effect of DINP and phenyl N-n-propylcarbamate on the hydrolysis of ethyl butyrate by mycobacteria

Suspensions of mycobacteria were incubated for $30 \mathrm{~min}$. at $\mathrm{pH} 7 \cdot 4$ and $37 \cdot 5^{\circ}$ with DINP, phenyl $N$ - $n$-propylcarbamate, or both inhibitors simultaneously, in the concentrations given. Subsequently a small volume of substrate was added and the esterase activity measured manometrically.

$$
\begin{array}{cc}
\text { Concn. of } & \begin{array}{c}
\text { Concn. of } \\
\text { DINP } \\
\text { (carbamate } \\
(-\log \mathrm{M})
\end{array} \\
(-\log \mathrm{M})
\end{array}
$$

(No inhibitor)
$\mathbf{8 . 0}$
$\mathbf{7 . 0}$
$\mathbf{6 . 0}$
$5 \cdot 0$
$4 \cdot 0$
3.0

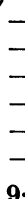

$\begin{array}{ll} & \\ - & 9 \cdot 0\end{array}$

$\begin{array}{ll}- & 8.0 \\ - & 7.0\end{array}$

二 $\quad 6.0$

- $\quad 5 \cdot 0$

- $\quad 4 \cdot 0$

- $\quad 3.0$

$5 \cdot 0 \quad-$

$5.0 \quad 8.0$

$5 \cdot 0 \quad 7 \cdot 0$

$5 \cdot 0 \quad 6 \cdot 0$

$5 \cdot 0$

- 6.0

$\overrightarrow{8.0} \quad 6.0$

$7 \cdot 0$

$6 \cdot 0$

$5 \cdot 0$

$4 \cdot 0$

3.0

Esterase activity towards ethyl butyrate ( $\mu \mathrm{l}$. of $\mathrm{CO}_{2} / \mathrm{mg}$. dry wt./hr.)

$\begin{array}{ccc}\text { Myco. phlei } & \text { Myco. B } & \text { Myco. E } \\ 120 & 75 & 115 \\ 104 & 75 & 105 \\ 60 & 73 & 56 \\ 24 & 59 & 11 \\ 22 & 28 & 1 \\ 11 & 9 & 0 \\ 2 & 2 & 0 \\ - & 74 & 104 \\ 118 & 69 & 58 \\ 111 & 45 & 12 \\ 98 & 19 & 3 \\ 72 & 15 & 1 \\ 22 & 14 & 0 \\ 4 & 7 & 0 \\ 22 & - & - \\ 20 & - & - \\ 13 & - & - \\ 1 & - & - \\ 0 & - & - \\ 98 & 19 & - \\ 83 & 19 & - \\ 38 & 19 & - \\ 2 & 18 & 8 \\ 1 & 16 & \\ - & 2 & \end{array}$

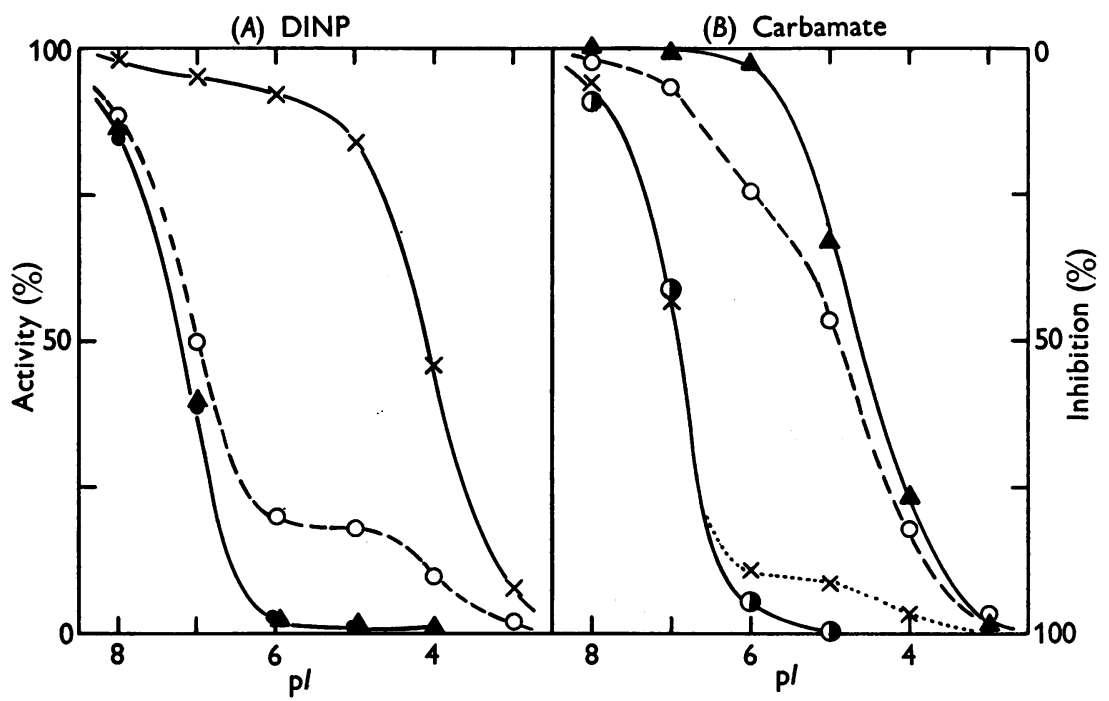

Fig. 1. Effect of DINP and phenyl $N$-n-propylcarbamate on the ali-esterases of $M y c o$. phlei. The values are calculated from the data given in Tables 2 and 3. Graph $\boldsymbol{A}$ demonstrates the effect of various concentrations of DINP on the total esterase activity towards butyranilide $(x)$, ethylleucine $(\Delta)$ and ethyl butyrate $(O)$, and on the residual activity towards ethyl butyrate which remains in the presence of $10^{-6} \mathrm{M}$ phenyl $N$ - $n$-propylcarbamate (0). Graph $B$ shows the results obtained in parallel experiments with various concentrations of phenyl $N$ - $n$-propylcarbamate; the same symbols are used but $(O)$ indicates the effect of the carbamate on the residual activity towards ethyl butyrate which remains in the presence of $10^{-5} \mathrm{M}$ DINP (see Table 2). 
Table 3. Effect of DINP and phenyl N-n-propylcarbamate on the hydrolysis of ethylleucine and butyranilide by mycobacteria

Suspensions of mycobacteria were incubated for $30 \mathrm{~min}$. at $\mathrm{pH} 7 \cdot 4$ and $37 \cdot 5^{\circ}$ with DINP or phenyl $N$ - $n$-propylcarbamate in the concentrations given. Subsequently a small volume of substrate was added and the esterase activity measured manometrically. The amount of mycobacteria used for each measurement was varied between 10 and $100 \mathrm{mg}$. dry weight depending on the magnitude of the esterase activity in question; the degree of inhibition produced did not appear to be markedly dependent on the amount of enzyme preparation employed.

Esterase activity ( $\mu \mathrm{l}$. of $\mathrm{CO}_{2} / \mathrm{mg}$. dry wt./hr.)

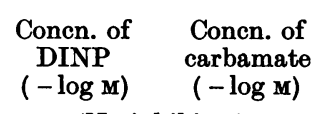
(No inhibitor)

$\begin{array}{ll}\mathbf{8} \cdot 0 & - \\ \mathbf{7} \cdot 0 & - \\ \mathbf{6} \cdot 0 & - \\ \mathbf{5 \cdot 0} & - \\ \mathbf{4} \cdot 0 & - \\ \mathbf{3 \cdot 0} & - \\ - & \mathbf{8 \cdot 0} \\ - & \mathbf{7 \cdot 0} \\ - & 6 \cdot 0 \\ - & 5 \cdot 0 \\ - & 4 \cdot 0 \\ - & 3 \cdot 0\end{array}$

\begin{tabular}{|c|c|}
\hline \multicolumn{2}{|c|}{ Myco. phlei } \\
\hline $\begin{array}{l}\text { Ethyl- } \\
\text { leucine }\end{array}$ & $\begin{array}{l}\text { Butyr- } \\
\text { anilide }\end{array}$ \\
\hline $25 \cdot 5$ & 9.5 \\
\hline $\begin{array}{r}22.1 \\
10.1 \\
0.5 \\
0.4 \\
0.2 \\
0.0\end{array}$ & $\begin{array}{l}9 \cdot 3 \\
9 \cdot 0 \\
8.7 \\
8.0 \\
4 \cdot 4 \\
0.8\end{array}$ \\
\hline $\begin{array}{r}25.5 \\
25 \cdot 3 \\
24.8 \\
17.0 \\
5.8 \\
0.4\end{array}$ & $\begin{array}{l}8.9 \\
5 \cdot 4 \\
1 \cdot 0 \\
0 \cdot 8 \\
0 \cdot 3 \\
0.0\end{array}$ \\
\hline
\end{tabular}

butyranilide is inhibited by a 100 -fold smaller concentration of this compound (Table 3). The results obtained with $M y c o$. A were qualitatively identical with those described above for Myco. B. With Myco. A and Myco. B as well as with Myco. phlei, therefore, a carbamate-sensitive enzyme is responsible for most of the activity towards butyranilide and a carbamate-resistant enzyme is responsible for most of the activity towards the ethyl ester of leucine. Although DINP rather than phenyl $N$ - $n$-propylcarbamate was used to distinguish between the two esterases of Myco. phlei (Table 2), these enzymes will be referred to as the carbamate-sensitive and carbamate-resistant esterases to stress the analogy with the esterases of Myco. A and Myco. B.

It might be noted that the activity towards butyranilide is probably not due completely to the carbamate-sensitive esterase; conversely, the carbamate-sensitive esterase may also be able to hydrolyse the ethyl ester of leucine slowly. The results given for Myco. phlei in Table 3 and Fig. 1 indicate that the carbamate-resistant esterase is probably responsible for about $10 \%$ of the total activity towards butyranilide; the results obtained with ethylleucine are less decisive but possibly the carbamate-sensitive esterase may be responsible for about $2 \%$ of the total activity of Myco. phlei towards this ester. Similarly, the carbamateresistant esterase of $M y c o$. B is probably responsible for about $1.5 \%$ of the total activity towards butyranilide (Table 3).

The esterase present in Myco. E can also be classified as a carbamate-sensitive enzyme (see Tables 2 and 3). This esterase appears to be responsible both for the very small activity of Myco. E towards ethylleucine and for the larger activity towards butyranilide (Table 3). The results obtained with Myco. C and Myco. D were again almost identical with those shown for Myco. $\mathrm{E}$ in Table 3.

The characteristics of the esterases described above are summarized in Table 4. This table shows the relative sensitivities of the esterases to inhibition by DINP and by phenyl $N$ - $n$-propylcarbamate, together with the approximate $\mathrm{p} I_{50}$ values (negative logarithm of the molar concentration of inhibitor required to produce $50 \%$ inhibition of the esterase activity); the $\mathrm{p} I_{50}$ values were calculated from results similar to those given in Tables 2 and 3 by a graphical plot of the type shown in Fig. 1. The results obtained with $\mathrm{E} 600$ in other experiments are also included in Table 4 for purposes of comparison.

The ali-esterases of the strains C, D and E exhibit similar characteristics with $\mathrm{E} 600$ as well as with the other two inhibitors (Table 4). However, the remainder of the esterases described here fail to show any marked resemblances in their sensitivities to these inhibitors. For comparative purposes, we also studied the DINP-sensitive esterase of rat brain (cf. Myers, 1956) under the same experimental conditions, as well as the ali-esterase of rat liver which is responsible for the hydrolysis of ethyl and phenyl butyrates by this tissue (ef. Aldridge, 1954); the results shown in Table 4 do not provide any' evidence of similarities between these enzymes. 
Table 4. Comparison of various ali-esterases in their sensitivity to three inhibitors

Enzyme suspensions were incubated for $30 \mathrm{~min}$. at $\mathrm{pH} 7 \cdot 4$ and $37 \cdot 5^{\circ}$ with the inhibitors before measuring the residual esterase activity; the type of result obtained is illustrated in Tables 2 and 3 . The relative inhibition of the various esterases by a critical concentration of inhibitor is designated as complete or almost complete $(++)$, partial $(+)$, and slight or insignificant ( 0 ) inhibition. The $I_{50}$ values $(-\log$. of the molar concentration of inhibitor required to produce $50 \%$ inhibition of the esterase activity) were estimated from the graphs shown in Fig. 1 and from similar plots of the results which were obtained with the other esterases indicated below. The values for the DINP-sensitive ali-esterase of rat brain were determined with $100 \mathrm{mg}$. fresh wt. of brain $/ 5 \mathrm{ml}$. of reaction mixture, with tributyrin as substrate (cf. Myers, 1956). The $I_{50}$ values for the ali-esterase of rat liver are highly dependent on the concentration of enzyme; the values given below were determined with phenyl butyrate as substrate with $0.4 \mathrm{mg}$. fresh wt. of liver/5 ml. of reaction mixture.

\begin{tabular}{|c|c|c|c|c|c|c|c|}
\hline & & \multicolumn{3}{|c|}{ Relative inhibition by } & \multicolumn{3}{|c|}{$\mathrm{p} I_{50}$ values } \\
\hline \multicolumn{2}{|c|}{ Esterase } & $10^{-6} \mathrm{M}$ phenyl & & & Phenyl & & \\
\hline Source & Classification & carbamate & DINP & $\mathrm{E} 600$ & carbamate & DINP & E600 \\
\hline Myco. C & Carbamate-sensitive & ++ & ++ & ++ & $7 \cdot 9$ & $6 \cdot 4$ & $6 \cdot 8$ \\
\hline Myco. D & Carbamate-sensitive & ++ & ++ & ++ & $8 \cdot 1$ & $6 \cdot 1$ & $7 \cdot 0$ \\
\hline Мyсо. E & Carbamate-sensitive & ++ & ++ & ++ & $8 \cdot 0$ & $6 \cdot 2$ & $7 \cdot 0$ \\
\hline Myco. phlei & Carbamate-sensitive & ++ & 0 & + & $6 \cdot 8$ & $4 \cdot 0$ & $5 \cdot 1$ \\
\hline Myco. phlei & Carbamate-resistant & 0 & ++ & ++ & $4 \cdot 5$ & $7 \cdot 2$ & $7 \cdot 8$ \\
\hline Мусо. А & Carbamate-sensitive & ++ & + & + & $7 \cdot 6$ & $4 \cdot \overline{8}$ & $5 \cdot 2$ \\
\hline Myco. A & Carbamate-resistant & 0 & 0 & + & $\mathbf{3} \cdot \mathbf{3}$ & $3 \cdot 9$ & $5 \cdot 0$ \\
\hline Мyсо. В & Carbamate-sensitive & ++ & + & ++ & $7 \cdot 0$ & $5 \cdot 5$ & $6 \cdot 8$ \\
\hline Мусо. В & Carbamate-resistant & 0 & $\mathbf{0}$ & ++ & $3 \cdot 1$ & $4 \cdot 0$ & $6 \cdot 1$ \\
\hline Rat brain & DINP-sensitive & 0 & ++ & ++ & $2 \cdot 6$ & $7 \cdot 3$ & $7 \cdot 4$ \\
\hline Rat liver & DINP-sensitive & + & ++ & ++ & $5 \cdot 7$ & $8 \cdot 9$ & $9 \cdot 0$ \\
\hline
\end{tabular}

\section{Substrate specificity of the ali-esterases}

On the basis of the differences between the esterases in their sensitivity to DINP and phenyl $N$ - $n$-propylcarbamate (Table 4), it is possible to distinguish the activities of each of these esterases and consequently to study their substrate specificities. The results obtained in this way are shown in Table 5. To facilitate comparison of these results the esterases have been grouped according to their sensitivity to inhibition by phenyl $N$-n-propylcarbamate. The brain esterase could also beclassified in the group of carbamate-resistant esterases (Table 4), whereas the ali-esterase of liver appears to occupy an intermediate position.

The results given in Table 5 show that the carbamate-sensitive esterases of Myco. C, D and E are not completely identical although they are very similar; on the basis of the results given in Tables 4 and 5, it does seem justified to consider these esterases as variations of one distinct enzyme. The carbamate-sensitive esterases of Myco. phlei and strains $A$ and $B$ also show some similarity to each other and to the esterases of strains C, D and $E$ (Table 5), even though they differ considerably in their sensitivities to inhibition by $\mathrm{E} 600$ and DINP (Table 4). The most striking differences in the relative substrate-specificity patterns are observed with the three phenyl-substituted esters; the rate of hydrolysis by the carbamate-sensitive esterases Myco. phlei and strains A and B decreases in the order ethyl $\beta$-phenylpropionate, ethyl phenylacetate, ethyl benzoate, whereas the rate of hydro- lysis by the carbamate-sensitive esterases of strains $\mathrm{C}, \mathrm{D}$ and $\mathrm{E}$ decreases in the reverse order, i.e. ethyl benzoate, ethyl phenylacetate, ethyl $\beta$-phenylpropionate.

The two carbamate-resistant esterases of $M y c o$. phlei and Myco. B also show some resemblance to each other and to the ali-esterase of rat liver, although the liver esterase appears to hydrolyse all of the ethyl esters more efficiently than do the bacterial esterases in question (Table 5). In contrast to the carbamate-sensitive esterases, all of these enzymes exhibit an appreciable activity towards ethylleucine and little activity towards butyranilide. The DINP-sensitive esterase of rat brain failed to exhibit an appreciable activity towards either of these substrates (Table 5), and would therefore not seem to be related to any of the esterases found in the saprophytic mycobacteria with the possible exception of the carbamateresistant esterase of Myco. A. This enzyme also exhibits an exceptional specificity pattern; it does not hydrolyse ethyl esters at an appreciable rate under the experimental conditions (Table 5.)

\section{DISCUSSION}

The present investigation was designed primarily to test the possible correlation between the effects of the organophosphorus compounds on the growth and on the ali-esterases of saprophytic mycobacteria. The classification of these ali-esterases was found to be more complicated than expected. However, the results show two general differences between the 
ali-esterases of Myco. phlei and strains A and B, on the one hand, and the ali-esterases of strains $C, D$ and $E$ on the other hand.

(1) Two distinct esterases can be identified in the bacilli whose growth is relatively resistant to inhibition by E600 and DINP, i.e. Myco. phlei and strains $A$ and $B$. On the other hand, only one esterase could be identified in the bacilli whose growth in the Dubos medium is readily inhibited by E 600 and DINP, i.e. strains C, D and E. The significance of this finding as an explanation for the effects of E 600 and DINP on the growth is open to some question. In the first place, it seems likely that the strains $\mathbf{C}, \mathrm{D}$ and $\mathbf{E}$ might also contain other esterases but that the amounts would be too small to be distinguished with the substrates and

Table 5. Comparison of the relative substrate specificities of the various ali-esterases

Activity of the ali-esterases towards tributyrin is expressed as $\mu \mathrm{l}$. of $\mathrm{CO}_{2} / \mathrm{mg}$. dry wt./hr., and the relative activity towards the other substrates is calculated as a percentage of the activity towards tributyrin. The values in parentheses were too low to be determined accurately; omission of a value indicates that the activity was not measured. In one case with $M y c o$. A and ethylleucine, it was not possible to obtain a reproducible value with different enzyme preparations. Most of the results on the relative substrate specificity of the DINP-sensitive, carbamate-resistant esterase of rat brain are taken from Myers (1956). The activities of each of these esterases were distinguished on the basis of their sensitivities to inhibition by DINP and phenyl $N$-n-propylcarbamate as indicated in Table 4.

Activity of the carbamate-sensitive esterases

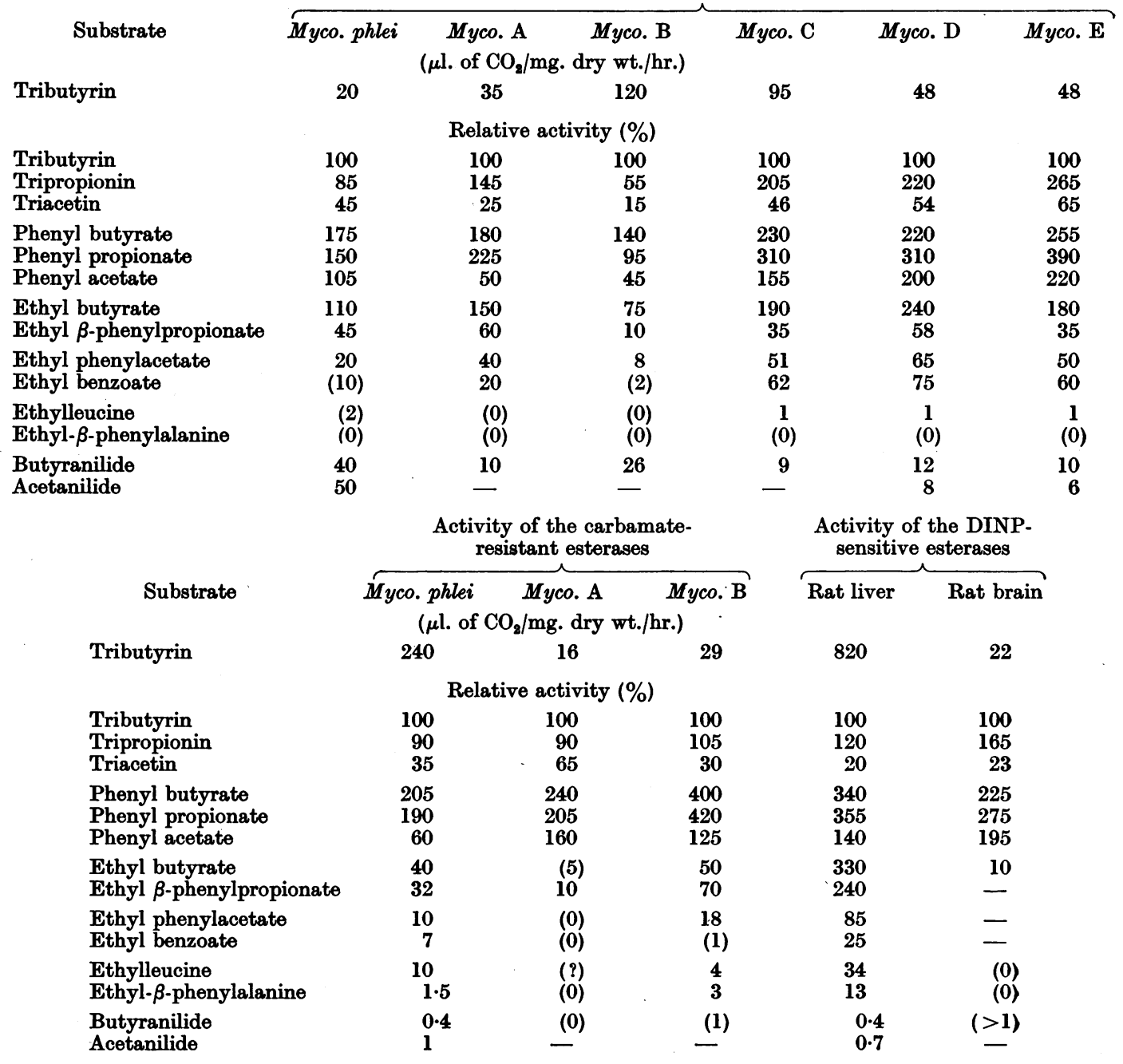


experimental methods used. Secondly, the carbamate resistant esterase of $M y c o . p h l e i$ is readily inhibited by $\mathrm{E} 600$ and DINP ; the carbamate-resistant esterase of $M y c o$. B is also fairly sensitive to inhibition by E600 (Table 4). This fact suggests that the presence of a carbamate-resistant esterase in these two strains of saprophytic mycobacteria could not explain the lack of effect of E600 on their growth.

(2) The carbamate-sensitive esterases of Myco. phle $i$ and the strains A and B act most efficiently on esters which have a larger acyl group than the esters which are hydrolysed most efficiently by the carbamate-sensitive esterases of the strains C, D and E. This difference is seen most clearly in the relative rates of hydrolysis of the three phenyl-substituted esters, as mentioned previously. It is possible, therefore, that the first group of esterases normally act on a substrate which has a larger acyl residue than the physiological substrate of the second group of esterases. The significance of this difference for the problem in question is uncertain; the remainder of the substrate-specificity pattern (Table 5) gives no indication that the general type of physiological substrate is essentially different.

The results of these experiments do not disprove the hypothesis that the effect of E600 and DINP on the growth of the mycobacteria is related to the effect of these inhibitors on the ali-esterase activity (cf. Mendel et al. 1953). If we compare the esterase activities of the mycobacteria whose growth is resistant to E600 and DINP with the esterase activities of the mycobacteria whose growth is readily prevented by these compounds under the conditions given in Table 1, we see that the general pattern of ali-esterase activity is the same in the members of each group, although differing from the general pattern of ali-esterase activity in the other group. This fact does suggest that the hypothesis may be correct.

It is not difficult to understand why the growth of the strains C, D and E could be prevented by the esterase inhibitors since the ali-esterases are readily inhibited by $\mathrm{E} 600$ and DINP. Moreover, the esterases of these mycobacteria hydrolyse butyranilide and acetanilide fairly efficiently (Table 5); this finding suggests that these enzymes have a function in protein metabolism, i.e. in the hydrolysis of peptide or amide derivatives or both (cf. Michel et al. 1937). Under these circumstances it would not be surprising that these enzymes should prove to be essential for the normal growth of the mycobacteria.

However, a problem remains in connexion with the fact that E600 and DINP have little effect on the growth of Myco. phlei and the strains A and B, even though certain of the ali-esterases concerned may be inhibited by these compounds. As indicated above, the presence of a second type of enzyme, the carbamate-resistant esterases, in these strains of saprophytic mycobacteria does not seem to provide a sufficient explanation of this problem. In $M y c o$. B both the carbamate-sensitive and the carbamateresistant esterases are fairly sensitive to inhibition by E600 (Table 4); both enzymes are almost completely inhibited by $10^{-5} \mathrm{M} \mathrm{E} 600$ within $30 \mathrm{~min}$. at $37 \cdot 5^{\circ}$, although this concentration of inhibitor has little effect on the growth of Myco. B (Table 1). A similar situation is encountered with Myco. phlei. The carbamate-sensitive esterase is less readily inhibited by $\mathrm{E} 600$ in this case; however, the carbamate-resistant esterase, which is responsible for the major portion of the activity towards tributyrin, ethyl butyrate and most of the other esters tested (Table 2 and 5), is highly sensitive to inhibition by E 600 and DINP (Table 4) and does not seem to be necessary for the growth of these bacilli (cf. Table 1). The results obtained with Myco. A are less significant since both esterases are moderately resistant to inhibition by E600 and DINP (Table 4), and since the carbamate-resistant esterase exhibits a different substrate specificity (Table 5).

We might comment on the similarity in the substrate-specificity patterns of the ali-esterase of rat liver and the carbamate-resistant esterases found in Myco. phlei and Myco. B. The physiological significance of the liver esterase is also obscure; this enzyme does not seem to be of any immediate importance either for the oxidative metabolism of liver slices or for the regeneration of the liver after partial hepatectomy (cf. Myers \& Mendel, 1953). Although we have little further information concerning the hydrolytic enzymes present in the mycobacteria, more extensive experiments have been carried out with liver preparations. Since the ali-esterase in liver seems to resemble the carbamate-resistant esterases in $M y c o . p h l e i$ and $M y c o . B$, with regard both to their substrate specificities (Table 5) (cf. Cohen, Kushnick \& Purdy, 1953) and their apparent dispensability for growth processes, it may be appropriate to discuss the enzymes in liver in more detail at this point.

Despite the fact that the ali-esterase of liver hydrolyses butyranilide fairly slowly (Table 5) and does not seem to exhibit any appreciable activity towards $N$-ethylbutyramide (Schwert \& Glaid, 1952), we would suggest that this enzyme may have a function in protein metabolism. The results obtained in other experiments with selective esterase inhibitors indicate that the liver esterase does hydrolyse butyramide slowly (Myers, Kemp, Tol \& de Jonge, unpublished results) and that it is probably identical with the liver amidase described by Bray, James, Thorpe \& Wasdell (1950) and Bray, White \& Wood (1955). In both cases, the enzyme activity shows an optimum between $\mathrm{pH} 8$ and 9 , and ex- 
hibits the phenomenon of excess-substrate inhibition (Bamann, 1929, 1931; Murray \& King, 1930; Bray et al. 1955). The activity of the amidase shows the following pattern, in decreasing order: caproamide, butyramide, acetamide, and $\gamma$-phenylbutyramide, $\beta$-phenylpropionamide, phenylacetamide, benzamide; this specificity pattern agrees well with the results reported above (Table 5), and by Sobotka \& Glick (1934) for the esterase activity of liver. The amidase appears to be present in the same fraction of the liver as the enzyme which hydrolyses $\beta$-phenylalaninamide and leucinamide (Meister, Levintow, Greenfield \& Abendschein, 1955). The similarity in the structure of these substrates suggests that the amidase activities towards $\beta$-phenylalaninamide and $\beta$-phenylpropionamide might well be due to the same enzyme; further experiments will be required to test the validity of this hypothesis.

The experimental results reported in the literature indicate that the liver contains at least two enzymes capable of hydrolysing leucinamide and $\beta$-phenylalaninamide. One of these enzymes, which is probably similar to the leucine aminopeptidase isolated from other tissues, is most active at a slightly acid $\mathrm{pH}$, is strongly activated by manganese ions, does not hydrolyse amino acid esters and is not inhibited by organophosphorus compounds (cf. Smith, 1951 $a, b$; Smith \& Spackman, 1955). The other enzyme is active at more alkaline $\mathrm{pH}$ values and does not seem to require activating ions (cf. Errera \& Greenstein, 1948; Meister et al. 1955). If, as we suggest, the latter enzyme is identical with the ali-esterase of liver, then it would be capable of hydrolysing esters as well as amide derivatives and would be sensitive to inhibition by organophosphorus compounds; similar properties have been demonstrated for other proteolytic enzymes such as trypsin and chymotrypsin (Neurath \& Schwert, 1950).

Under these circumstances it is conceivable that complete inhibition of the liver ali-esterase by organophosphorus compounds might not have any obvious influence on the metabolism of this tissue, since the liver also contains another enzyme which is capable of hydrolysing the amino acid amides and which is not affected by the organophosphorus compounds. This seems at present to be the most logical explanation of the results mentioned above which we obtained previously in an investigation of the liver ali-esterase (Myers \& Mendel, 1953). It is possible that an analogous situation might explain the results reported here for Myco. phlei and Myco. B.

The peptidases of mycobacteria have been studied by Roulet \& Zeller $(1945,1948)$, but the connexion between the enzymes which they described and the ali-esterases described above is still a matter for speculation. If, as we suggest, the carbamate-resistant and the carbamate-sensitive esterases of the mycobacteria may both be concerned with the hydrolysis of amides or peptides or both, a further study of the activity of these enzymes towards amino acid derivatives would be valuable in elucidating their physiological functions. It is to be expected that these investigations would shed further light on the reason for the differences observed in the effects of E600 and DINP on the growth of these mycobacteria.

\section{SUMMARY}

1. It had been observed that the growth of certain strains of saprophytic mycobacteria was prevented by organophosphorus compounds in low concentrations, whereas the growth of other strains of saprophytic mycobacteria was not affected under the same experimental conditions (Ruys, unpublished results). This observation provided an opportunity to investigate the suggested correlation between the effects of the organophosphorus compounds on the growth and on the esterase activities of the mycobacteria (Mendel et al. 1953).

2. Studies on the substrate specificities and sensitivities of these enzymes to inhibitors showed distinct differences between the ali-esterases of the two groups of mycobacteria. The significance of these differences is discussed.

3. The ali-esterases of the mycobacteria, like the ali-esterase of liver, are capable of hydrolysing a wide variety of esters, including amino acid esters as well as certain amides. It is suggested therefore that these enzymes might have a function in protein metabolism. On this basis it is possible to offer an explanation for the differences in the effects of the organosphosphorus compounds on growth.

The authors are much indebted to Professors B. Mendel and A. Charlotte Ruys for their interest in this investigation; we are also indebted to Professor Ruys for supplying us with the results obtained in preliminary growth experiments with the saprophytic mycobacteria.

\section{REFERENCES}

Aldridge, W. N. (1953). Biochem. J. 53, 117. Aldridge, W. N. (1954). Biochem. J. 57, 692.

Bamann, E. (1929). Hoppe-Seyl. Z. 183, 149.

Bamann, E. (1931). Hoppe-Seyl. Z. 194, 1.

Bray, H. G., James, S. P., Thorpe, W. V. \& Wasdell, M. R. (1950). Biochem. J. 47, 294.

Bray, H. G., White, K. \& Wood, P. B. (1955). Biochem. J. $59,167$.

Brooks, V. B., Ransmeier, R. E. \& Gerard, R. W. (1949). Amer. J. Physiol. 157, 299.

Cohen, S., Kushnick, J. B. \& Purdy, C. V. (1953). J. Bact. 66, 266.

Dubos, R. J. \& Davis, B. D. (1946). J. exp. Med. 83, 409.

Dubos, R. J. \& Middlebrook, G. (1947). Amer. Rev. Tuberc. $56,334$. 
Errera, M. \& Greenstein, J. P. (1948). J. nat. Cancer Inst. 8, 71.

Falconer, J. S. \& Taylor, D. B. (1946). Biochem. J. 40, 831.

Fodor, P. (1946). Nature, Lond., 158, 375.

Gerhardt, C. (1853). Liebigs Ann. 87, 149.

Kobezen, M. J., Metcalf, R. L. \& Fuhuto, T. R. (1954). J. agric. Food Chem. 2, 864.

Löwenstein, E. (1930). Dtsch. med. Wschr. 56, 1010.

Meister, A., Levintow, L., Greenfield, R. E. \& Abendschein, P. A. (1955). J. biol. Chem. 215, 441.

Mendel, B., Myers, D. K., Uyldert, I. E., Ruys, A. C. \& de Bruyn, W. M. (1953). Brit. J. Pharmacol. 8, 217.

Michel, H. O., Bernheim, F. \& Bernheim, M. L. C. (1937). J. Pharmacol. 61, 321.

Murray, D. R. P. \& King, C. G. (1930). Biochem. J. 24, 190. Myers, D. K. (1956). Biochem. J. 64, 740.

Myers, D. K. \& Mendel, B. (1953). Biochem. J. 53, 16.

Myers, D. K., Schotte, A., Boer, H. \& Borsje-Bakker, H. (1955). Biochem. J. 61, 521.
Neurath, H. \& Schwert, G. W. (1950). Chem. Rev. 46, 69.

Proskauer, B. \& Beck, M. (1894). Z. Hyg. InfektKr. 18, 128.

Roulet, F. \& Zeller, E. A. (1945). Experientia, 1, 122.

Roulet, F. \& Zeller, E. A. (1948). Helv. chim. acta, 31, 1915.

Ruys, A. C. (1954). Leeuwenhoek ned. Tijdschr. 20, 145.

Schroeter, G. (1909). Ber. dtsch. chem. Ges. 42, 3356.

Schwert, G. W. \& Glaid, A. J. (1952). J.biol. Chem. 199, 613.

Smith, E. L. (1951a). Advanc. Enzymol. 12, 191.

Smith, E. L. (1951 b). In The Enzymes, vol. 1, part 2, p. 793. Ed. by Sumner, J. B. \& Myrbäck, K. New York: Academic Press.

Smith, E. L. \& Spackman, D. H. (1955). J. biol. Chem. 212, 271.

Sobotka, H. \& Glick, D. (1934). J. biol. Chem. 105, 199.

Wislicenus, W. (1897). Liebigs Ann. 296, 361.

Youmans, G. P. \& Karlson, A. G. (1947). Amer. Rev. Tuberc. 55, 529.

\title{
Studies on Ali-esterases
}

\section{SELECTIVE INHIBITORS OF THE ESTERASES OF BRAIN AND SAPROPHYTIC MYCOBACTERIA*}

\author{
BY D. K. MYERS, $\dagger$ A. KEMP JUN., JUSTINA W. TOL AND MARIA H. T. DE JONGE \\ Pharmaco-therapeutic Laboratory, University of Amsterdam, Amsterdam, Holland
}

(Received 26 June 1956)

Previous investigations have shown that the growth of Mycobacterium tuberculosis and certain strains of saprophytic mycobacteria can be prevented in vitro by certain organophosphorus compounds (Mendel, Myers, Uyldert, Ruys \& de Bruyn, 1953; Ruys, 1954 ; Myers, Tol \& de Jonge, 1957); it was suggested that the effect of these compounds on growth may be related to their ability to inhibit the ali-esterases of these mycobacteria. The organophosphorus compounds which were used in these experiments cannot be used for the same purpose in vivo since they are also potent inhibitors of true cholinesterase and are consequently highly toxic to animals. In an attempt to find more selective inhibitors of the ali-esterases, a series of compounds was synthesized and tested initially against the true cholinesterase and ali-esterase of rat brain. Some of the results obtained in these preliminary experiments have been reported previously (Myers, Mendel, Gersmann \& Ketelaar, 1952; Mendel et al. 1953; Myers, 1953, 1954 ; Myers \& Kemp, 1954).

In the present work a number of new inhibitory compounds were prepared and investigated as inhibitors of the ali-esterases of the saprophytic

* Part 5: Myers, Tol \& de Jonge (1957).

$\dagger$ Present address: Suffield Experimental Station, Ralston, Alberta, Canada. mycobacteria and of the esterases of rat brain in vitro. The results obtained appear to offer valuable information concerning the factors which govern the selectivity of these inhibitors towards a given esterase.

\section{EXPERIMENTAL}

Determination of esterase activity. Esterase activity was measured by a manometric method in the Warburg apparatus at $37.5^{\circ}$ and $\mathrm{pH} 7.4$ in a medium containing $0.025 \mathrm{M}-\mathrm{NaHCO}_{3}$ and saturated with $\mathrm{CO}_{2}+\mathrm{N}_{2}(5: 95, \mathrm{v} / \mathrm{v})$. The reaction mixture was incubated for $30 \mathrm{~min}$. at $37.5^{\circ}$, with or without added inhibitor, before adding a small volume of substrate to determine the residual esterase activity. The ali-esterase activities were measured with $0.2 \%(w / v)$ of tributyrin as substrate and the true cholinesterase activity of rat brain with $0.03 \mathrm{M}$ acetyl- $\beta$-methylcholine. All values were corrected for the very slow spontaneous hydrolysis of the substrate in question under the same experimental conditions.

The enzyme preparations used were described in previous publications (Myers, 1956b; Myers et al. 1957); for comparative purposes, we have tested the true cholinesterase and ali-esterase of rat-brain homogenates, and the aliesterases of five strains of saprophytic mycobacteria. Two of these strains, Mycobacterium phlei and Myco. B, are not affected by the organophosphorus compounds in their growth at $37^{\circ}$ in the medium of Dubos \& Davis (1946), even though the ali-esterase activity is inhibited (Myers et al. 1957); the growth of the other three strains, which were 